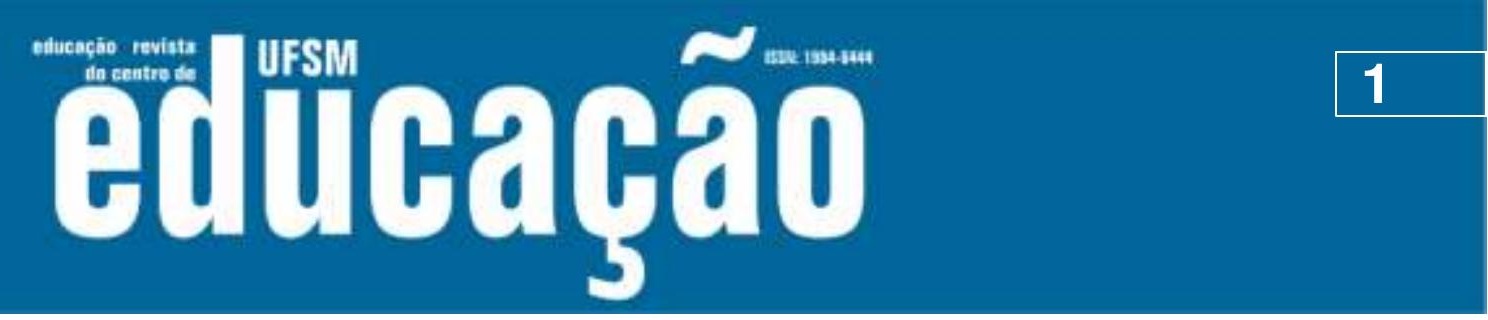

ISSN: 1984-6444 | http://dx.doi.org/10.5902/1984644423919

\title{
Diretrizes para orientar a formulação e implementação de ações de Design na Extensão Universitária
}

\author{
Guidelines to guide the formulation and implementation of Design \\ actions in University Extension
}

André Luis Marques da Silveira

Professor doutor do curso de Design da Pontifícia Universidade Católica do Rio Grande do Sul, Porto Alegre, Rio Grande do Sul, Brasil.

Gabriela Würzius Zambenedetti

Mestre em Design pelo Centro Universitário Ritter dos Reis, Porto Alegre, Rio Grande do Sul, Brasil

\section{Vinicius Gadis Ribeiro}

Professor adjunto da Universidade Federal do Rio Grande do Sul, Porto Alegre, Rio Grande do Sul, Brasil.

Endereço: Pontifícia Universidade Católica do Rio Grande do Sul, Escola de Comunicação, Artes e Design - Famecos. Av. Ipiranga, 6681 - Prédio 07. CEP: 90619900. Porto Alegre, Rio Grande do Sul, Brasil.

E-mail: andre.silveira@pucrs.br - gabriela_wurzius@gmail.com vinicius.gadis@ufrgs.br

Recebido em 10 de setembro de 2016

Aprovado em 02 de janeiro de 2018

\section{RESUMO}

Este artigo aborda a temática da extensão universitária na educação brasileira. Metodologicamente, baseia-se na revisão da bibliografia concernente a temática abordada. Apresenta o conceito de extensão universitária e reflete sobre o valor da ação extensionista no âmbito do design, a partir de uma perspectiva dialógica que busca a superação de problemas e o desenvolvimento social. Ao longo do texto, propõe-se um quadro de diretrizes para o auxílio nas práticas extensionistas no campo do design, a saber: Diretrizes gerais para a prática extensionista; Diretrizes para o ensino-aprendizagem na extensão, enquanto espaço formativo para aquisição de 


\section{Lusm oittrapa}

ISSN: 1984-6444 | http://dx.doi.org/10.5902/1984644423919

Para dar conta desse objetivo, os autores do presente artigo buscaram subsídios na teoria para propor um quadro de diretrizes para criação e análise de ações extensionistas no campo do design. Esse quadro foi dividido em três dimensões de diretrizes: a primeira se refere à prática extensionista brasileira em geral; a segunda, ao ensino-aprendizagem; e, por fim, a terceira busca identificar abordagens de Design mais consoantes com as finalidades da extensão universitária.

Dessa forma, na segunda seção, aborda-se a história da extensão universitária e concebe-se um primeiro esboço, designado "Diretrizes gerais para a prática extensionista". Após, na terceira seção, investiga-se o ensino-aprendizagem na extensão universitária, o trabalho comunitário e as metodologias participativas. Nesse momento, concebe-se a segunda dimensão de diretrizes designada de "Diretrizes para o ensino-aprendizagem na extensão". Na quarta seção, por fim, reflete-se sobre as práticas do Design que mais se aproximam dos valores da atividade extensionista, culminando na terceira e última dimensão do quadro proposto, a saber "Diretrizes para o Design na extensão".

\section{Diretrizes gerais para a prática extensionista no Brasil}

O surgimento de práticas de extensão no Brasil coincide com a criação do ensino superior. As primeiras atividades extensionistas aconteceram através de cursos e conferências na Universidade de São Paulo, em 1911, e de prestações de serviços da Escola Superior de Agricultura e Veterinária de Viçosa na década de 1920. Em 1931, o Estatuto da Universidade Brasileira normatiza a extensão. Em 1961, ela é incorporada à primeira Lei de Diretrizes e Bases da Educação Nacional. Nesse período, a extensão era vista como difusão de conhecimento a partir de cursos e palestras com o objetivo de aumentar o nível cultural da população.

Entretanto, o conceito de extensão universitária vem se modificando ao longo das décadas. As suas concepções iniciais enfatizavam a transferência de conhecimento das instituições de ensino superior para a sociedade, que aparecia de forma passiva, somente para receber o que a universidade oferece. Portanto, ao invés de construir junto com a comunidade, a ideia inicial de extensão residia em construir para a comunidade. 


\section{U

ISSN: 1984-6444 | http://dx.doi.org/10.5902/1984644423919

sujeito que participa de uma relação dialógica. Através dessas ideias centrais, a Extensão Universitária passou a ser discutida como prática participativa de troca de saberes entre universidade e sociedade.

Na década de 1980, a prática de extensão passa a ser repensada. O caráter assistencialista foi questionado em favor da concepção de extensão como um processo de troca de saberes, que integra o ensino e a pesquisa e que apoia os movimentos sociais (NOGUEIRA, 2005). Em 1996, em resposta à indissociabilidade entre Ensino, Pesquisa e Extensão prevista na Constituição, a Lei de Diretrizes e Bases da Educação Nacional (LDB) (Lei n. 9.394/1996) determina a Extensão Universitária como uma das finalidades da Universidade (Art. 43) e apresenta a possibilidade de apoio financeiro do Poder Público, incluindo-se bolsas de estudo (Artigos 44, 52, 53 e 77) (FÓRUM..., 2012).

Conforme essas novas definições, a extensão tem o papel não somente de democratizar o conhecimento, mas também de buscar uma participação da comunidade na troca e produção de saberes, inserindo a pesquisa acadêmica na realidade brasileira e permitindo que os cidadãos se tornem sujeitos na construção do conhecimento, e não apenas objetos de estudo ou de transmissão de conhecimento. Assim, a extensão deve ser uma prática que interliga ensino e pesquisa com as demandas sociais, possibilitando a formação de profissionais cidadãos e fornecendo as bases da produção de conhecimentos para a superação de desigualdades sociais (NOGUEIRA, 2005).

A atual Política Nacional de Extensão Universitária (2012) apresenta cinco diretrizes orientadoras para a criação e implementação de ações na extensão universitária. São elas:

a) Interação Dialógica;

b) Interdisciplinaridade e Interprofissionalidade;

c) Indissociabilidade Ensino-Pesquisa-Extensão;

d) Impacto na Formação do Estudante e Impacto;

e) Transformação Social.

As três primeiras diretrizes (a, b, c) são o principal insumo para a primeira dimensão do quadro de diretrizes proposto pelos autores, referente à prática 


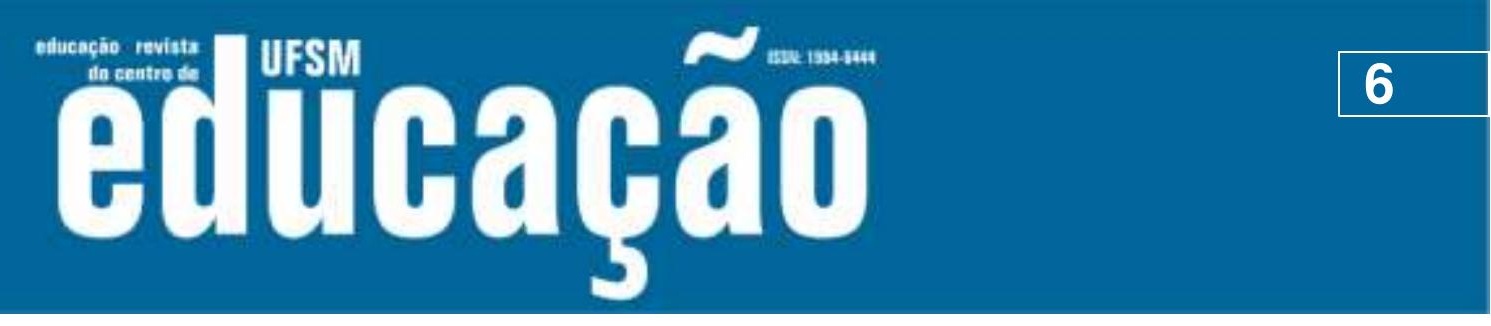

ISSN: 1984-6444 | http://dx.doi.org/10.5902/1984644423919

extensionista em geral. As duas últimas (d, e) são consideradas nas demais dimensões do quadro ("Diretrizes para o Ensino-Aprendizagem na Extensão" e "Diretrizes para o Design na Extensão").

A seguir, apresenta-se a primeira dimensão do quadro de diretrizes para análise de projetos extensionistas na área do design.

Quadro 1 - Diretrizes Gerais para a Prática Extensionista

\section{Diretrizes gerais para a Prática Extensionista}

Estas diretrizes orientam a criação e implementação de ações na extensão por meio de interação dialógica, da interdisciplinaridade e da interprofissionalidade, da Interação entre ensino, pesquisa e extensão. Também expressam os princípios e valores sociais da prática universitária quanto ao bem comum, a sociabilização do conhecimento, a diversidade cultural e participação comunitária.

\begin{tabular}{|l|l|l|}
\hline O que & Por que & Como \\
\hline Interação Dialógica & $\begin{array}{l}\text { Para construir o conhecimento } \\
\text { junto com a sociedade, } \\
\text { privilegiando os espaços de } \\
\text { comunicação e troca de saberes } \\
\text { acadêmicos e populares com o } \\
\text { objetivo de enfrentar as questões } \\
\text { sociais que assolam o país. }\end{array}$ & $\begin{array}{l}\text { Criando espaços para o debate } \\
\text { com organizações sociais, } \\
\text { entidades de classe e a } \\
\text { comunidade em geral quanto as } \\
\text { soluções para os problemas que } \\
\text { assolam a sociedade. }\end{array}$ \\
\hline $\begin{array}{l}\text { Interdisciplinaridade e } \\
\text { Interprofissionalidade }\end{array}$ & $\begin{array}{l}\text { Para integrar os conhecimentos } \\
\text { das diversas áreas do saber } \\
\text { acadêmico e da prática profissional } \\
\text { com vistas a enriquecer as } \\
\text { vivências e os resultados das } \\
\text { ações de extensão. }\end{array}$ & $\begin{array}{l}\text { Fomentando a participação de } \\
\text { professores e estudantes de } \\
\text { diversos cursos nos projetos e } \\
\text { oportunizando o contato com } \\
\text { profissionais do mercado e do } \\
\text { terceiro setor. }\end{array}$ \\
\hline $\begin{array}{l}\text { Interação entre ensino, } \\
\text { pesquisa e extensão }\end{array}$ & $\begin{array}{l}\text { Para exercer o princípio da } \\
\text { indissociabilidade entre ensino, } \\
\text { pesquisa e extensão, com vistas a } \\
\text { alcançar uma maior unidade entre } \\
\text { teoria e prática, oportunizando aos } \\
\text { estudantes o contato com a } \\
\text { realidade local. }\end{array}$ & $\begin{array}{l}\text { Utilizando metodologias } \\
\text { participativas para melhorar a } \\
\text { apreensão de saberes e a } \\
\text { aproximação com as } \\
\text { comunidades, além de incorporar } \\
\text { à pós-graduação ações de } \\
\text { extensão, fortalecendo a } \\
\text { produção acadêmica. }\end{array}$ \\
\hline
\end{tabular}

Fonte: elaborado pelos autores com aportes da Política Nacional de Extensão Universitária (FORPROEX, 2012). 


\section{FusM eutuarao

ISSN: 1984-6444 | http://dx.doi.org/10.5902/1984644423919

Com o intuito de estabelecer a segunda dimensão de diretrizes, buscou-se identificar as abordagens teóricas relacionadas ao processo de ensino-aprendizagem na extensão universitária. Pensa-se a extensão como um processo de educação não formal, que mobiliza os conhecimentos dos estudantes em relação aos problemas do mundo real.

\section{Aspectos teóricos e diretrizes para o ensino-aprendizagem na extensão universitária}

Segundo Síveres (2013), a aprendizagem na extensão abre horizontes para um conhecimento mais criativo, inovador, compreensivo, reflexivo, produtivo, inventivo, interdisciplinar e complexo. Pode-se dizer que a experiência extensionista agrega uma dimensão de autonomia e pró-atividade, uma vez que os atores exercem papeis ativos nas ações, atuando como sujeitos do próprio processo de aprendizagem.

Segundo Costa et. al (2013), há três dimensões de aprendizagem na extensão: 1) aprendizagem para a formação profissional; 2) aprendizagem para a convivência coletiva e inclusão social; 3) aprendizagem para valores e construção cidadã. $\mathrm{Na}$ primeira, os estudantes entram em contato com a realidade da profissão, identificam novas áreas de atuação e, principalmente, conseguem relacionar teoria e prática através de vivências significativas. Na segunda, destaca-se o trabalho em equipe, a colaboração, a troca e a convivência com culturas diferentes. Na última dimensão, considera-se que a extensão oferta um espaço privilegiado para o exercício da cidadania e atuação dos estudantes frente aos problemas sociais. Ao afirmar-se que a experiência extensionista propicia essas três dimensões de aprendizagem, em especial na vivência com comunidades e culturas de fora da instituição, entende-se que também se caracteriza como um espaço para experimentação de novas formas de ensinar e aprender.

Anastasiou e Alves (2006) defendem que, em um mundo cada vez mais complexo - feito de constantes mudanças no tecido social -, não faz sentido manter as mesmas práticas docentes do século passado, baseadas em memorização como operação principal. Para enfrentar os desafios da complexidade, deve-se evoluir para 


\section{U usm

ISSN: 1984-6444 | http://dx.doi.org/10.5902/1984644423919

atenta para a importância das metodologias participativas nos trabalhos de extensão com as comunidades externas. Para o autor, hoje está sendo construída uma nova extensão posta a serviço da sociedade, dentro de uma visão compromissada de atuação, concretizada em iniciativas sociais e solidárias. Para isso, a elaboração de ações de extensão requer subsídios da metodologia participativa (THIOLLENT et al., 2003, p.65).

A ideia de extensão como prestação de serviços, ou seja, como ação pontual para "clientes" externos tem sido repensada principalmente por conta da inexistência de efeitos a longo prazo. Isso porque melhorias duradouras ultrapassam resultados temporários e demandam envolvimento da comunidade e mudança de atitude, somente possíveis através da participação. No decorrer da ação extensionista, a participação deve ser facilitada e fortalecida. É importante que se crie um espaço de comunicação onde todos tenham voz. Pode-se constatar uma evolução na participação quando há alguma forma de empoderamento dos atores em relação às ações, ou seja, quando as pessoas têm atitudes que mostram autonomia e próatividade nas tarefas (THIOLLENT et al., 2003).

O FORPROEX (FÓRUM..., 2012, p.18) afirma que as metodologias participativas são a principal base da extensão. "Apenas ações extensionistas com esses formatos permitem aos atores nelas envolvidos a apreensão de saberes e práticas ainda não sistematizados e a aproximação aos valores e princípios que orientam as comunidades", pois é na participação que se vivenciam novas possibilidades de ação e se incorpora o conhecimento de atitudes criativas e próativas. A participação também dá sentido aos resultados, uma vez que são alcançados através de um entendimento construído de forma coletiva.

Silva (2013) entende que o elemento de participação envolve o conceito de cidadania, em um cenário de qualificação dos processos democráticos. Para o autor, é exatamente na sociedade civil que se deve focar a atuação da extensão universitária. Quando os estudantes extensionistas têm a oportunidade de protagonizar ações participativas na sociedade é que eles estão exercitando plenamente o conceito de cidadania. 


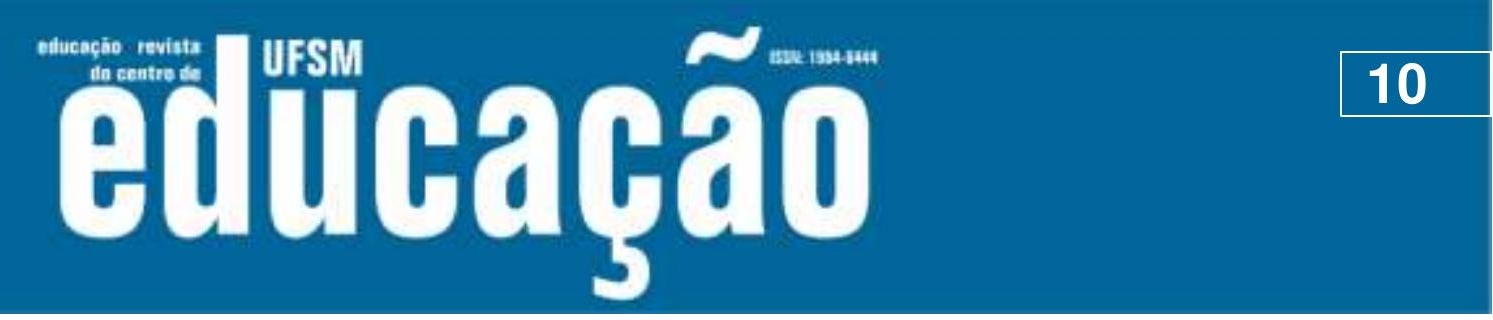

ISSN: 1984-6444 | http://dx.doi.org/10.5902/1984644423919

A seguir, apresenta-se a segunda dimensão do quadro de diretrizes. As diretrizes concebidas são derivadas das categorias propostas por Costa et al. (2013), e se fundamentam na noção de construção de um espaço de protagonismo no processo de aprendizagem que possibilita aos sujeitos (professor, alunos e comunidade) desempenharem papeis ativos nos projetos (SÍVERES, 2013). Além disto, a terceira diretriz, "Exercício da cidadania", se vale da ideia de trabalho comunitário na extensão posta por Abranches (2014) e também inclui a diretriz orientadora "Impacto na formação do estudante", sugerida pelo Fórum de Pró-Reitores de Extensão (FÓRUM..., 2012). A quarta diretriz, baseia-se em Anastasiou e Alves (2006).

Quadro 2 - Diretrizes para o Ensino-aprendizagem na Extensão

\begin{tabular}{|l|l|l|}
\hline \multicolumn{3}{|c|}{ Diretrizes para o Ensino-aprendizagem na Extensão } \\
\hline \multicolumn{2}{|c|}{$\begin{array}{l}\text { Estas diretrizes consideram a atividade de extensão como um espaço não formal de } \\
\text { aprendizagem, } \\
\text { convivência coletiva, do exercício da cidadania e inclusão social, do exercício de estratégias } \\
\text { participativas para aquisição de conhecimento. }\end{array}$} \\
\hline O que & Por que & Como \\
\hline Âmbito profissional & $\begin{array}{l}\text { Para ofertar ao estudante a } \\
\text { oportunidade de entrar em contato } \\
\text { com a realidade da profissão, ao } \\
\text { mesmo tempo em que vivencia o } \\
\text { potencial social do conhecimento } \\
\text { que adquire na sala de aula. }\end{array}$ & $\begin{array}{l}\text { Relacionando as atividades } \\
\text { extensionistas ao cenário } \\
\text { profissional e estabelecendo } \\
\text { parcerias com profissionais da } \\
\text { área. }\end{array}$ \\
\hline Convivência coletiva & $\begin{array}{l}\text { Para oportunizar o trabalhar em } \\
\text { equipe, a colaboração, a } \\
\text { convivência com culturas } \\
\text { diferentes, a identificação de } \\
\text { solução para os problemas que } \\
\text { assolam a comunidade. }\end{array}$ & $\begin{array}{l}\text { Fomentando o trabalho e o diálogo. } \\
\text { Oportunizando a troca com o } \\
\text { usuário e com profissionais de } \\
\text { instituições parceiras. }\end{array}$ \\
\hline $\begin{array}{l}\text { Exercício da } \\
\text { cidadania }\end{array}$ & $\begin{array}{l}\text { Para promover o contato do } \\
\text { estudante com as questões sociais } \\
\text { que assolam a sociedade com o } \\
\text { intuito de formar estudantes para } \\
\text { que tenham uma formação técnica, } \\
\text { cidadã e humana. }\end{array}$ & $\begin{array}{l}\text { Dialogando com os moradores das } \\
\text { comunidades atendidas para } \\
\text { propor formas de combater os } \\
\text { problemas sociais identificados. }\end{array}$ \\
\hline
\end{tabular}




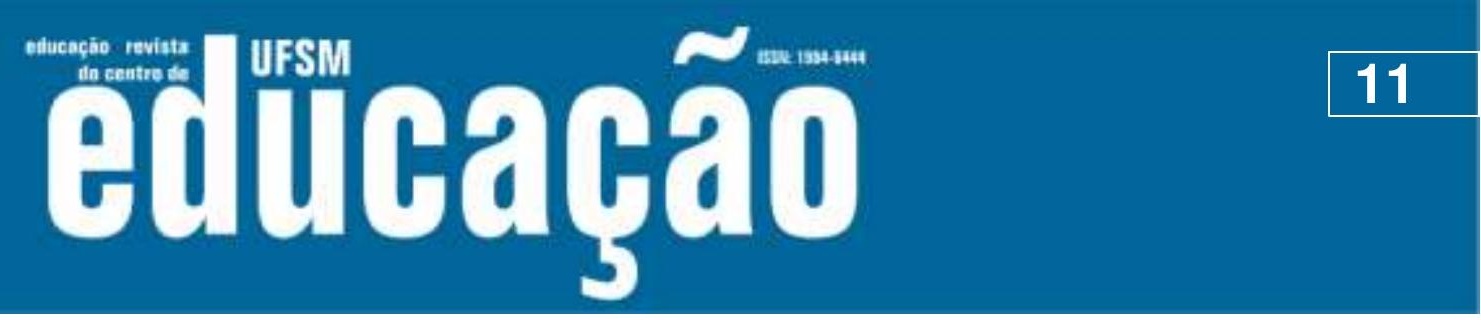

ISSN: 1984-6444 | http://dx.doi.org/10.5902/1984644423919

\begin{tabular}{|l|l|l|}
\hline $\begin{array}{l}\text { Estratégias } \\
\text { participativas de } \\
\text { ensino-aprendizagem }\end{array}$ & $\begin{array}{l}\text { Para enfrentar os desafios da } \\
\text { atualidade através de práticas } \\
\text { participativas de } \\
\text { ensino-aprendizagem. A } \\
\text { aprendizagem não deve se focar } \\
\text { apenas no conteúdo, mas também, } \\
\text { nos processos coletivos de } \\
\text { construção de saberes. }\end{array}$ & $\begin{array}{l}\text { Escolhendo ferramentas mais } \\
\text { adequadas para a apropriação do } \\
\text { conhecimento e o desenvolvimento } \\
\text { da autonomia. Possibilitando a } \\
\text { construção coletiva das aulas e } \\
\text { dando espaço para criatividade, } \\
\text { espontaneidade e experimentação. }\end{array}$ \\
\end{tabular}

Fonte: elaborado pelos autores com aportes teóricos de Costa et al. (2013), Síveres (2013), Abranches (2014), Fórum... (2012) e Anastasiou e Alves (2006).

Para estabelecer a terceira dimensão de diretrizes, buscou-se identificar abordagens teóricas de design mais alinhadas aos valores da extensão universitária.

\section{Diretrizes para o design na extensão}

$\mathrm{Na}$ sua acepção mais ampla, o design pode ser considerado uma prática projetual para resolver problemas complexos, utilizando-se de uma abordagem interdisciplinar e de uma visão sistêmica, apoiada por uma cultura de projeto (GALISAI; BORBA; GIORGI; 2008). Não se vincula só e necessariamente a objetivos econômicos ou empresariais, pois também possui habilidades para trabalhar com projetos de natureza social (HASLINGER, 2007).

Em um país como o Brasil, marcado por desigualdades sociais, as atividades extensionistas em comunidades de baixa renda têm um papel fundamental ao buscarem um diálogo e um fazer relevante entre academia e comunidade, impulsionando melhorias sociais. É nesse sentido que os objetivos da extensão aproximam-se das potencialidades de impacto do design, um campo essencialmente prático-projetual e interdisciplinar capaz de interferir fortemente no contexto social.

Embora todo o tipo de atividade projetual possa trazer melhorias e atuar no contexto da extensão universitária, buscou-se as abordagens mais voltadas ao objetivo de atuação social, participativa e dialógica para comporem o quadro de diretrizes. São elas: 1) Design social; 2) Design centrado no humano; 3) Design participativo. Essas três abordagens podem se apoiar para construir ações extensionistas que levem em conta uma atuação humana, empática e colaborativa. 


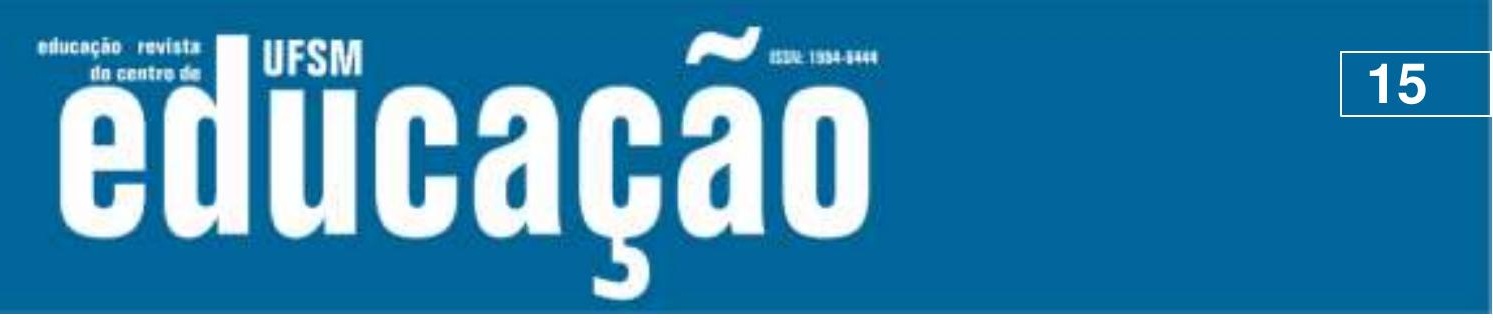

ISSN: 1984-6444 | http://dx.doi.org/10.5902/1984644423919

Muitos estudantes mencionaram o sentimento do ganho pessoal em aplicar habilidades de design em prol do social como o fator mais importante para que continuassem no projeto. Um dos estudantes, por exemplo, que quando entrou "não se importava" com questões sociais, viu no design social o motivo de permanência por mais de dois anos no projeto.

\begin{abstract}
A gente está dentro de uma grande empresa, que são os Bancos Sociais, a gente faz projetos em grupo e o diferencial é justamente o social, tu se importar. [...] esse diferencial, o social, que me fez ficar no DSA. Achei melhor continuar nele do que fazer um estágio. $E$ agora eu tenho certeza que alguma coisa da minha profissão vai ser relacionada ao design social. Isso a gente não aprende na sala de aula. [...] o DSA fez com que eu tentasse colocar isso dentro do design de moda, que é uma coisa muito importante. Toda a cadeia da moda, trabalho escravo e tudo mais, o design social abriu meu olho e agora eu sinto que sou uma pessoa mais correta. [...] Pegar os recursos que tu aprendeu na faculdade e fazer com que isso ajude alguém. Pensar na experiência do usuário, pensar no próximo. Não pensar só no lucro, não só uma cadeia de produção, mas uma cadeia que ajude o próximo, que melhore a vida das pessoas. (Aluno $\mathrm{G}$ ).
\end{abstract}

A natureza do trabalho social gera um impacto no estudante que ultrapassa a formação acadêmica e técnica, despertando reflexões pessoais sobre a realidade e ampliando a perspectiva de atuação profissional. Os estudantes sentem a diferença positiva dos projetos na vida das pessoas, pois vivem o retorno dos seus esforços e entendem a responsabilidade das ações extensionistas.

Eu gosto de poder fazer alguma diferença, mesmo que pouca, na vida das pessoas. Tipo uma criança que vai numa penitenciária visitar os pais e, quando ela está na biblioteca, naquele espaço que a gente criou, ela esquece daquelas coisas ruins que ela teve que passar até chegar a ver a mãe. Ela esqueceu aquele mundo por um segundo e está lá, mexendo com um livro. Eu gosto do resultado, de fazer aquilo que, por menos tempo que seja, fez a diferença um pouquinho na vida das pessoas. (Aluno G).

Nesse projeto de extensão é legal isso que tu pode pôr em prática e ainda aprender a conviver realmente em grupo [...]. E na faculdade tu não aprende, porque é diferente, lá tu decide sobre um trabalho para entregar para a faculdade e deu. E ali tu está decidindo sobre como isso vai interferir na vida das pessoas, então a responsabilidade é maior e a discussão é mais séria. (Aluno C).

Os professores também são impactados pela experiência extensionista. Embora haja o reconhecimento da docência na graduação, as questões humanas vivenciadas na extensão aprofundam os laços entre estudantes e professores e tornam as relações mais significativas para ambos.

O que eu busco é que tanto eu quanto os estudantes tenhamos uma relação de compartilhamento, de construção de uma sociedade mais justa, mais 


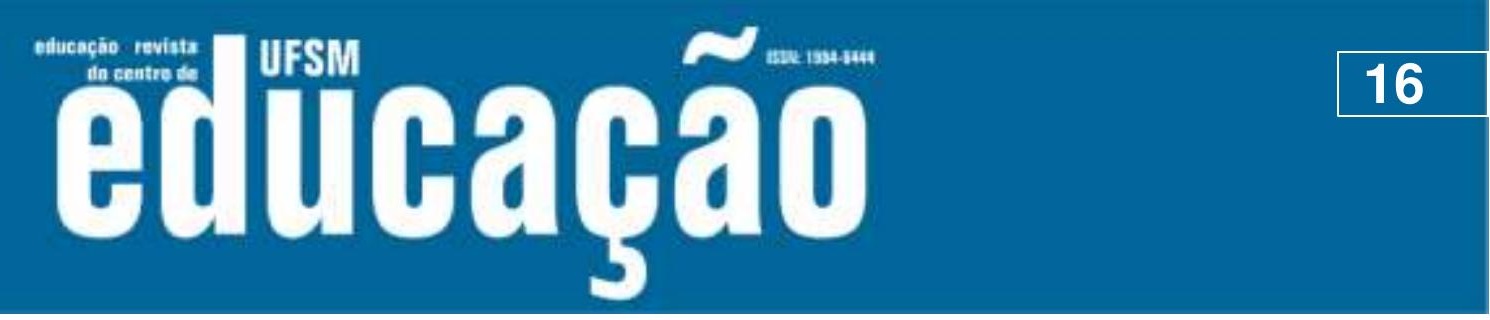

ISSN: 1984-6444 | http://dx.doi.org/10.5902/1984644423919

humana [...] os estudantes que passaram por aqui se transformam, dá para perceber que algo muda neles, que tem alguma situação que não é de ensino, que é algo pessoal. Tem coisas que a gente não consegue ensinar. Acontecem. (Professor A).

Juntar as pessoas no mesmo espaço, cada um com seus sonhos [...]. Então o DSA mexe muito com a gente, questão humana. De pensar eu estou no meu conforto e as pessoas vagando nos espaços [...]. Tu tens vontade de fazer mais e mais e mais e mais. Tive a oportunidade de entrar em uma penitenciária que é uma coisa tri tabu para a nossa sociedade [...]. Se um daqueles presos pegar um livro já está bom. (Professor B).

Uma das perguntas do instrumento de entrevistas solicitava que os entrevistados escolhessem cinco palavras que representassem a experiência vivida no projeto. Seguem abaixo as respostas, organizadas com a ferramenta Wordle.

Figura 1 - Palavras para a experiência extensionista no DSA

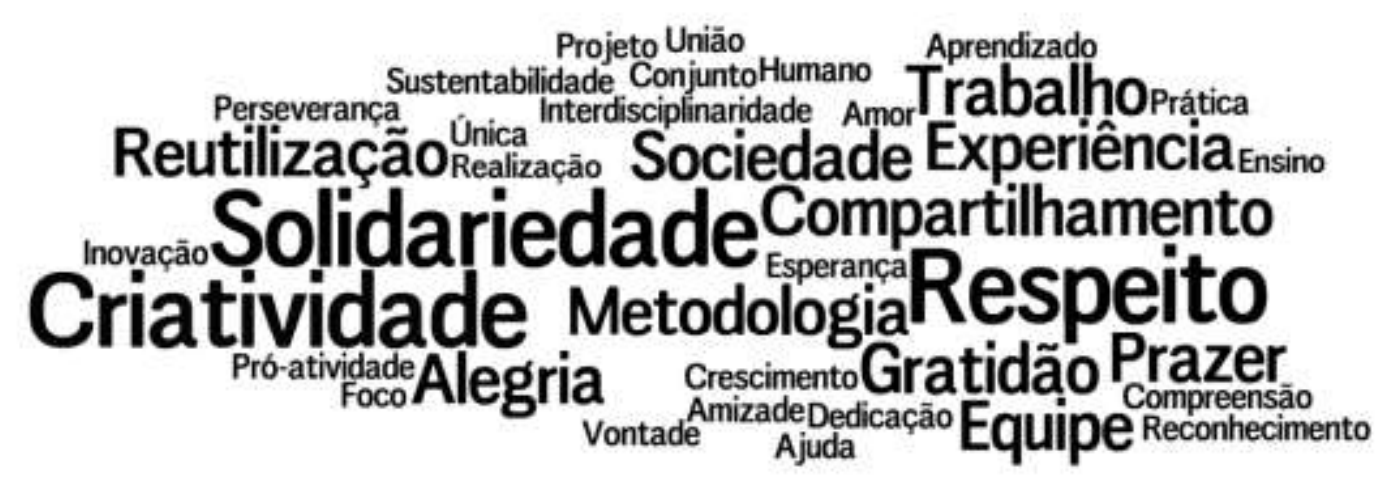

Fonte: desenvolvida pelos autores a partir da ferramenta Wordle..

O tamanho das palavras está relacionado à frequência. As palavras menores foram citadas uma vez, as de tamanho médio, duas vezes, e as de tamanho maior, três vezes. Nota-se que as palavras mais citadas foram criatividade, solidariedade e respeito. Tendo em vista que a maior parte das palavras vêm dos estudantes (pois foram a maioria entrevistada), é possível refletir sobre possíveis diferenças entre as palavras presentes nessa figura em relação a palavras que descreveriam experiências em um projeto de sala de aula ou um projeto de estágio no mercado.

Os relatos de estudantes e professores revelam vivências positivas e potencialmente transformadoras, em especial devido ao contato com as diferentes realidades sociais do Brasil e seus múltiplos atores, que não estão presentes dentro 


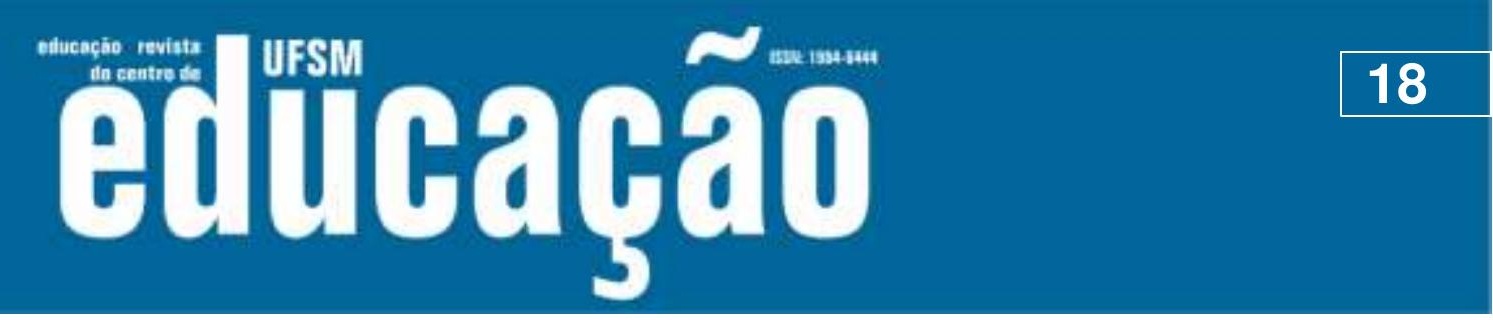

ISSN: 1984-6444 | http://dx.doi.org/10.5902/1984644423919

das potencialidades da sua futura profissão.

Almejando o crescimento da atuação do design na extensão universitária, esta pesquisa identificou, como primeiro passo, diretrizes para a ação na extensão universitária no contexto de ensino-aprendizagem do design. Entende-se que elas sistematizam princípios gerais, enfoques para o processo de ensino-aprendizagem e perspectivas teóricas para a ação do Design na extensão. Além disto, elas devem ser pensadas como um material de apoio ao avaliador, proponente ou participante de uma ação extensionista. Podem também ser utilizadas para proceder-se uma avaliação por uma pessoa externa ao projeto, ou uma reflexão dos atores quanto as práticas de ação adotadas. Destaca-se que a proposição possui três dimensões principais de análise: das diretrizes gerais para a prática extensionista; das diretrizes para o ensinoaprendizagem na extensão e das diretrizes para o Design na extensão.

\section{Referências}

ABRANCHES, M. Política Nacional de Extensão Universitária - 2012: Identidade e diretriz para a prática extensionista no ensino superior brasileiro. In: SILVA, L. D.; CÂNDIDO, J. G. (orgs.) Extensão universitária: conceitos, propostas e provocações. São Bernardo do Campo: Universidade Metodista de São Paulo, 2014.

ANASTASIOU, L. G; ALVES, L. P. Processos de ensinagem na Universidade: pressupostos para as estratégias de trabalho em aula. Joinville: Univille, 2006.

BONSIEPE, G. Design, Cultura e Sociedade. São Paulo: Blucher, 2011.

BRASIL. Lei de Diretrizes e Bases de Educação Brasileira. Lei ํㅜ 4.024, de 20 de dezembro de 1961.

BURNS, C.; COTTAM, H.; VANSTONE, C.; WINHALL, J. Transformation design. RED paper 02. Design Council: Londres, 2006.

CARDOSO, R. Uma introdução à história do design. São Paulo: Blucher, 2008.

CIPOLLA, C.; BARTHOLO, R. Empathy or inclusion: a dialogical approach to socially responsible design. International Journal of Design. vol.8, n.2, p.87-100. 2014.

COSTA, A. A. C.; BAIOTTO, C. R.; GARCES, S. B. B. Aprendizagem: o olhar da extensão. In: SÍVERES, L. (org.) A extensão universitária como um princípio de aprendizagem. Brasília: Líber Livro, 2013.

FÓRUM DE PRÓ-REITORES DE EXTENSÃO DAS INSTITUIÇÕES DE EDUCAÇÃO SUPERIOR PÚBLICAS BRASILEIRAS. Política Nacional de Extensão Universitária. Manaus, AM. Maio de 2012. 


\section{ussm Eutua

ISSN: 1984-6444 | http://dx.doi.org/10.5902/1984644423919

FREIRE, K. M.; BORBA, G. S. ; DIEBOLD, L. P. Participatory design as an approach to social innovation. Design Philosophy Papers. v. 2, p. 1-10, 2011. FREIRE, P. Extensão ou comunicação? São Paulo: Paz e Terra, 1977. GALISAI, R.; BORBA, G. S.; GIORGI, R. F. Design como cultura de projeto e como integração entre universidade e empresa. Porto Alegre, 2008.

HASLINGER, S. Social. In: ERLOFF, M.; MARSHALL, T. (Orgs.) Design dictionary: perspectives on design terminology. Berlin: Birkhäuser, 2007. p.366-369.

HO, D. K. L.; LEE, Y. C. The quality of design participation: intersubjectivity in design practice. International Journal of Design. vol.6, n.1, p.71-82. 2012.

IDEO. What is Human-centered design? Design Kit, 2015. Disponível em: <http://www.designkit.org/human-centered-design>. Acesso em jul. 2015.

KRIPPENDORFF, K. Design centrado no ser humano: uma necessidade cultural. Estudos em Design, Rio de Janeiro, v.8, n.3, p.87-88, set.-dez. 2000. Disponível em: <http://ow.ly/sE6p0>. Acesso em: mai. 2015.

MANZINI, E. Making things happen: social innovation and design. Design Issues. v.30, n.1, p.57-66. 2014.

MARGOLIN, V; MARGOLIN, S. Um "Modelo Social” de design: questões de prática e pesquisa. Revista Design em Foco. Salvador, 2004. julho-dezembro,vol.I, número 001. pp 43-48.

NOGUEIRA, M. D. Extensão universitária no Brasil: uma revisão conceitual. In: FARIA, D. S. (org.) Construção conceitual da extensão universitária na América Latina. Brasília: UNB, 2001.

NOGUEIRA, M. D. Políticas de extensão universitária brasileira. Belo Horizonte: UFMG, 2005.

OLIVEIRA, M. M.; CERQUEIRA, F.; CIDADE, M. L. R.; COSTA, E. S. C.; DIAS, V. L. N.; FARIAS, M. G.; NORA, C. M. D.; RAITZ, C. S.; SCHMITT, N. C.; DA SILVA, R. A. L. Refletindo sobre a extensão e suas práticas. Geografia Ensino e Pesquisa. vol.16, n.3, p.149-156. set.-dez. 2012.

PAPANEK, V. Design for the real world: human ecology and social change. Londres: Thames \& Hudson, 2006.

SANDERS, E. B. N. An evolving map of design practice and design research. Interactions. v.15 issue 6, p.13-17, nov.-dez. 2008.

SANDERS, E. B. N.; STAPPERS, P. J.. Co-creation and the new landscapes of design. CoDesign: International Journal of CoCreation in Design and the Arts. London, 2008. 4:1, 5-18.

SILVA, E. W. Fortalecendo a cultura cidadã dos estudantes - um dos papeis da extensão na universidade. In: SÍVERES, L. (org.) A extensão universitária como um princípio de aprendizagem. Brasília: Líber Livro, 2013. 


\section{T= Usm $\sim$

ISSN: 1984-6444 | http://dx.doi.org/10.5902/1984644423919

SÍVERES, L. (org.) A extensão universitária como um princípio de aprendizagem. Brasília: Líber Livro, 2013.

SPINUZZI, C. The methodology of participatory design. Technical Communication, v. 52, n. 2, p. 163-174, 2005.

THIOLLENT, M.; BRANCO, A. L. C.; GUIMARÃES, R. G. M.; FILHO, T. A. (orgs.) Extensão universitária: conceitos, métodos e práticas. Rio de Janeiro: Universidade Federal de Rio de Janeiro, 2003.

ZAMBENEDETTI, Gabriela Würzius. O design e a extensão universitária: proposta de diretrizes para análise de projetos extensionistas em comunidades de baixa renda. 119 f. Dissertação (Mestrado) - Centro Universitário Ritter dos Reis, Curso de Pós-Graduação de Design, Porto Alegre, 2016.

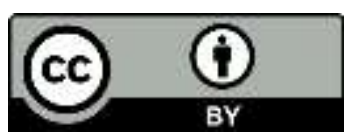

This work is licensed under a Creative Commons Attribution 4.0 International (CC BY 4.0). 